\title{
Riscos e incertezas: a realidade pós-extração do minério de chumbo em Boquira, BA
}

Risks and uncertainties: post-extraction reality of lead ore in Boquira, BA

\author{
Risques et incertitudes: la réalité après I'extraction du minerai de plomb dans \\ la ville de Boquira, $\mathrm{BA}$
}

Riesgos e incertezas: la realidad post-extracción del mineral plomo en Boquira, BA

\author{
Álvaro Antônio Xavier de Andrade* \\ Emanuelle Mercês Barros Soares* \\ Dênis Antônio da Cunha* \\ Marcelo Leles Romarco de Oliveira*
}

Recebido em 07/07/2016; revisado e aprovado em 31/10/2016; aceito em 28/11/2016

DOI: http:/ / dx.doi.org/10.20435/1984-042X-2017-v.18-n.1(08)

\begin{abstract}
Resumo: Este artigo tem por objetivo expor a realidade pós-extração do minério de chumbo no município de Boquira, Bahia. Os dados foram levantados por meio de pesquisas bibliográficas e de campo, alicerçadas pela metodologia qualitativa para entrevistar atores locais. Constatou-se a insuficiência de estudos científicos e ações governamentais que comprovem ou mensurem a contaminação na região. Diante disso, torna-se necessário realizar estudos que possibilitem um diagnóstico conclusivo sobre a situação em Boquira.

Palavras-chave: injustiça ambiental; inação governamental; desenvolvimento local.

Abstract: This article aims to expose a reality of lead ore post-extraction in Boquira City Bahia. The data were obtained through bibliographic search and field research based on qualitative methodology to interview local actors. It was found insufficient scientific studies and governmental actions that prove or measure the contamination in the region. Therefore, it is necessary conduct studies allowing conclusive diagnosis about this situation in Boquira.
\end{abstract}

Key words: environmental injustice; government inaction; local development.

Résumé: Cet article a pour but d'exposer la réalité après I'extraction du minerai de plomb dans la ville de Boquira, Bahia. Les données utilisées ont été recueillies à travers les recherches bibliographiques lesquelles nos base la méthodologie qualitative pour interviewer les acteurs locaux. II a été constaté une insuffisance dans les etudes scientifiques et dans les actions gouvernementales qui prouvent ou mesurent la contamination dans la region. Por consequent, it est nécessaire de mener des etudes pour une évaluation conclusive de la situation à Boquira.

Mots-clés: injustice environnementale; i'inaction gouvernementale; développment local.

Resumo: Este artículo tiene como objetivo exponer la realidad de la post-extracción del mineral plomo en el municipio de Boquira, Bahia. Los datos fueron obtenidos mediante búsquedas bibliográficas y de campo, usando como base una metodología cualitativa para entrevistar los actores locales. Se constató la insuficiencia de estudios científicos y acciones guvernamentales que comprueben o midan la contaminación en la región. Frente a esto, es necesario realizar estudios que posibiliten un diagnóstico concluyente sobre la situación en Boquira.

Palabras clave: injusticia ambiental; inacción gouvernamental; el desarrolho local.

\section{INTRODUÇÃO}

A referência de que a atividade mineradora é essencial e indispensável para o bem-estar da sociedade contemporânea, colaborando para manter o atual padrão de vida e de consumo, é comumente exposta tanto nos mais diversos meios de comunicação quanto na literatura (FARIAS, 2002; FERRAN, 2007). De fato, as matérias-primas oriundas dessa atividade estão presentes de diversas formas

\footnotetext{
* Universidade Federal de Viçosa, Viçosa, Minas Gerais, Brasil.
} 
no cotidiano e são fundamentais para a manutenção do atual estilo de vida, estando presentes em uma gama de produtos imprescindíveis na atualidade: transportes, eletrodomésticos, indústria farmacológica etc.

Contudo, também é comum os meios de comunicação e a literatura apresentarem diferentes problemas oriundos da mineração (MOREIRA; MOREIRA, 2004; SOUZA; LIMA, 2012). Se a atividade mineradora não for conduzida seguindo normas de segurança e, concomitantemente à extração, não forem realizadas as devidas ações para evitar a contaminação ambiental, a extração mineral pode ser responsável por causar grandes impactos socioambientais, dentre eles a poluição da água, do ar e do solo (FARIAS, 2002).

A situação pode se tornar ainda mais complexa quando a extração envolve os chamados "metais pesados", que, segundo Guilherme et al. (2005), são elementos com densidade atômica maior que 5,0 $\mathrm{g} \mathrm{cm}^{-3}$, ou massa atômica maior que 20, como é o caso do chumbo $(\mathrm{Pb})$. Esses autores destacam que, mesmo em pequenas concentrações, os metais pesados são tóxicos e podem causar sérios danos ao meio ambiente. Assim, nos últimos anos, têm-se intensificado as pesquisas com o objetivo de avaliar o destino do $\mathrm{Pb}$ nos solos após sua extração, uma vez que sua vida útil nesse ambiente é muito extensa, variando de 740 até 5.900 anos. Esse fato aumenta a possibilidade de acumulação desse elemento nos solos, potencializa a contaminação dos lençóis freáticos, torna-o mais disponível para absorção radicular pelas plantas e, consequentemente, potencializa sua entrada na cadeia alimentar, podendo causar sérios danos à saúde humana (MCBRIDE, 1994; DUARTE; PASQUAL, 2000; OLIVEIRA; HORN, 2006; OLIVEIRA, 2008; MARTINS et al., 2014).

Diante dessa realidade, surgiu o interesse em expor a situação de Boquira, no semiárido baiano. A origem desse municí- pio está ligada à descoberta e extração do $\mathrm{Pb}$ na década de 1950. Durante o auge do período de extração, que durou até meados da década de 1980, a mina de Boquira, por suas reservas e teor do minério, foi a mais importante do Brasil (SOBRAL et al., 2012). Com o encerramento da atividade mineradora, os rejeitos oriundos da extração foram abandonados em uma grande pilha sem que fossem adotadas as devidas medidas mitigadoras previstas pela legislação ambiental brasileira.

Apesar de a extração mineral ter sido totalmente interrompida há mais de 20 anos, o plano de recuperação das áreas degradadas nunca foi implementado. Mesmo com o risco eminente de contaminação, o lixão municipal foi instalado na superfície da pilha de rejeitos. Além disso, a presença de bairros urbanos, de catadores de materiais recicláveis no lixão e de estabelecimentos rurais próximos ao local da pilha de rejeitos pode consistir em problema de saúde pública, delineando-se um quadro de injustiça ambiental.

Para Porto (2005), a expressão “injustiça ambiental" representa as externalidades negativas a que populações locais, geralmente pobres e discriminadas, como pequenos agricultores, negros e índios, são submetidas em prol de um modelo de desenvolvimento caracterizado por grandes investimentos que têm por objetivo a apropriação dos recursos existentes em distintos territórios. Esse modelo, além de expor trabalhadores, habitantes e ecossistemas locais a sérios riscos de saúde e integridade, é responsável pela concentração de renda, uma vez que os lucros oriundos da extração desses recursos se concentram nas mãos de poucos atores, na maioria das vezes, externos às comunidades. Sendo assim, muitas vezes as populações locais são esquecidas pelas discussões públicas (PORTO, 2005) e ações governamentais, não podendo sequer opinar sobre as decisões que afetam seus cotidianos, tais quais as externalidades negativas oriundas da extração mineral. 
Diante disso, o objetivo deste artigo é expor a atual situação do município de Boquira em relação aos resquícios da atividade de extração de $\mathrm{Pb}$. Após a realizar uma vasta pesquisa bibliográfica, pôde-se constar que são poucos os trabalhos sobre os resquícios da atividade de extração do $\mathrm{Pb}$ no município de Boquira, e que estes foram realizados apenas na pilha de rejeitos e comprovaram a existência de elementos poluentes que potencializam a existência da contaminação. Por exemplo, o próprio $\mathrm{Pb}$ encontrado em altas porcentagens. Contudo, a falta de estudos científicos que mensurem a concentração desses elementos e a forma em que se encontram no meio ambiente como um todo limita os fatos aqui apresentados a indícios que apontam para a existência da contaminação na região.

Assim, no intuito de atingir seu objetivo, o artigo foi estruturado em cinco seções, além desta introdução e das considerações finais. A segunda seção apresenta os procedimentos metodológicos utilizados. A terceira traz algumas características do município de Boquira. A quarta expõe o início da extração de $\mathrm{Pb}$, apresenta breve caracterização do comportamento desse mineral na natureza, relata alguns riscos que ele pode trazer à saúde humana, conceitua injustiça ambiental e alinha a atual situação em Boquira com esse conceito. A quinta seção expõe as percepções dos atores locais que participaram da pesquisa sobre a possibilidade da contaminação.

\section{PROCEDIMENTOSMETODOLÓGICOS}

Considerando que atualmente a maior parte da população de Boquira está ocupada no setor agrícola, majoritariamente composto pela agricultura familiar, optou-se, como recorte metodológico neste trabalho, por ouvir os agricultores que fornecem alimentos via Programa Nacional de Alimentação Escolar (PNAE). O PNAE, entre outros objetivos, visa ao fornecimento de alimentos com padrões técnicos de qualidade predefinidos por Chamadas Públicas. A escolha por agricultores que acessavam esse programa ocorreu com o intuito de facilitar o acesso dos pesquisadores aos sujeitos inseridos no setor agrícola local. Além dos agricultores, também participaram da pesquisa o gestor municipal, que atuou como Engenheiro de Minas na mineradora que extraiu o $\mathrm{Pb}$ em Boquira; os secretários municipais de educação, meio ambiente, agricultura e de saúde; a nutricionista responsável por elaborar os cardápios da merenda escolar; um médico que trabalhou durante quinze anos na mineradora; e um representante municipal do Serviço Autônomo de Água e Esgoto (SAAE).

A pesquisa buscou identificar quais conhecimentos e percepções esses atores possuem em relação à possibilidade de contaminação no município proveniente da extração do $\mathrm{Pb}$. O levantamento dos dados foi realizado por meio de pesquisas bibliográficas e de campo, sendo que os trabalhos de campo ocorreram em três etapas no município de Boquira, nos anos de 2013, 2014 e 2016. Nessas oportunidades, foram entrevistados 17 atores locais. Como técnica de coleta de dados, utilizou-se a metodologia qualitativa. Essa escolha é explicada tendo por base a perspectiva de Flick (2009), na qual o autor descreve que a metodologia qualitativa busca captar conhecimentos e perspectivas dos entrevistados em relação à questão em estudo.

Dessa forma, no intuito de obter informações para que o objetivo deste artigo fosse alcançado, utilizou-se a entrevista semiestruturada não dirigida com os agricultores familiares. Para Marconi e Lakatos (2007), essa técnica possibilita que o entrevistador tenha liberdade para desenvolver cada situação específica na direção que julgar mais adequada. Ademais, possibilita ao entrevistado ter liberdade para manifestar livremente suas opiniões.

Com os demais participantes, o levantamento das informações ocorreu via 
e-mail, com as perguntas sendo elaboradas à medida que a pesquisa bibliográfica avançava e trazia novas informações sobre a história e a atual situação pós-extração do $\mathrm{Pb}$. Buscando captar também as percepções e conhecimentos desses agentes acerca da questão em estudo, utilizou-se perguntas abertas, o que, segundo Marconi e Lacatos (2003), permite aos informantes responder livremente e com o uso de linguagem própria, garantindo assim a emissão livre de opiniões. É importante destacar que já havia sido feito contato prévio com esses atores e que, portanto, eles já estavam cientes dos objetivos da pesquisa, antes do envio das perguntas.

\section{CARACTERÍSTICAS GEOGRÁFICAS E SOCIOECONÔMICAS DE BOQUIRA}

O município está localizado a 655 km de Salvador, capital do estado da Bahia. Possui área de $1.482,651 \mathrm{~km}^{2} \mathrm{e}$ população de 22.042 habitantes. O clima é subúmido a seco, a temperatura média anual é de $23,8^{\circ} \mathrm{C}$ e a pluviosidade anual de 894,8 milímetros. Em 2008, o Produto Interno Bruto (PIB) apresentou-se da seguinte forma: indústria - $\mathrm{R} \$ 6,96$ milhões; agropecuária - R \$ 7,56 milhões; setor de serviços (administração pública e atividades governamentais) $\mathrm{R} \$ 47,88$ milhões (SUPERINTENDÊNCIA DE ESTUDOS ECONÔMICOS E SOCIAIS DA BAHIA [SEI], 2011).

Segundo o Programa das Nações Unidas para o Desenvolvimento (PNUD, 2013), a maior parte da população $(66,6 \%)$ residia na zona rural. Além disso, aproximadamente $60 \%$ da população estava ligada ao tema da pobreza (13.225 habitantes). A ocupação dos maiores de 18 anos é apresentada na figura 1. Constata-se que o setor agropecuário é o principal responsável pela ocupação da população. Segundo o Censo Agropecuário (INSTITUTO BRASILEIRO DEGEOGRAFIA E ESTATÍSTICA [IBGE], 2006 ), existem no município 2.914 estabelecimentos da agricultura familiar $(95,8 \%)$ enquanto os estabelecimentos não familiares são apenas $128(4,2 \%)$.

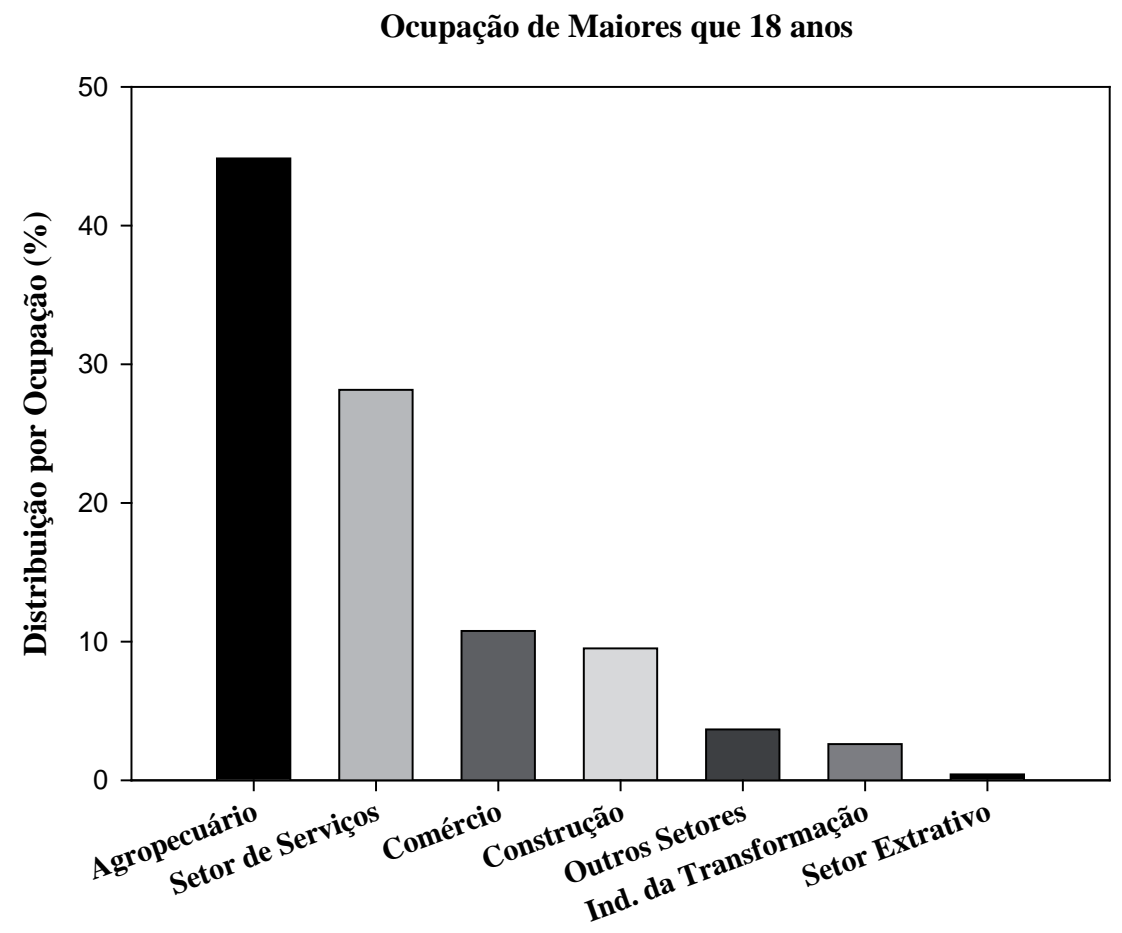

Figura 1 - Ocupação dos maiores de 18 anos por setor

Fonte: Elaborada pelos autores com base nos dados do Atlas Brasil (PNUD, 2013). 
Tal cenário caracteriza a agricultura, principalmente a familiar, como principal alternativa de emprego e renda de Boquira. Alinhando a grande porcentagem da população ligada ao tema da pobreza a essa realidade, percebe-se que a atividade agrícola gera pouca renda financeira, conforme constatou Andrade et al. (2015).

\section{A EXTRAÇÃO DO MINÉRIO DE CHUMBO}

Segundo Camelo (2006, p. 84-85), o início da atividade mineradora em Boquira "provocou, pouco tempo depois, uma série de reclamações de residentes locais, em relação à morte de gado bovino e equino e à perda de produção de hortas". $\mathrm{O}$ minério de $\mathrm{Pb}$ lá extraído era transportado em caminhões para Santo Amaro, BA, cidade distante 500 quilômetros de Boquira. Em Santo Amaro, a Companhia Brasileira de Chumbo (Cobrac), vinculada à mineradora Plubum, produzia ligas de Pb e exportava o Zn que era extraído junto com o Pb (SOUZA; LIMA, 2012).

A extração mineral promoveu o crescimento, trouxe prosperidade e fama ao município de Boquira. Paralelo à mineração, desenvolveram-se melhorias na infraestrutura local, foram criadas novas estradas, escolas, farmácias, ambulatórios, entre outros (FERRAN, 2007). Entretanto o apogeu da mineração durou pouco mais de 30 anos. Em 1986, com a extração em fase final, uma vez que as melhores reservas tinham sido extraídas, a mineração foi vendida ao grupo CMP, associado do grupo Luxma (SOBRAL et al., 2012).

Segundo Ferran (2007), a Luxma teve a extração focada nos chamados pilares de sustentação, áreas que tinham de ser poupadas para assegurar a sustentação das galerias abertas no subsolo. Contudo, para cada pilar de sustentação explorado, a empresa, por questões de segurança, era obrigada a construir um pilar artificial, o que tornou inviável a continuidade das atividades devido aos custos. Aliado a isso, a grande oferta internacional de $\mathrm{Pb}$ colaborou para que a mina, que chegou a operar com mais de mil funcionários, tivesse seus equipamentos transferidos para outras minas que a empresa explorava, demitindo todos os funcionários e fechando suas portas. Esse fato, segundo Camelo (2006), ocorreu em 1992.

\subsection{O chumbo na natureza e os riscos à saúde humana}

Apesar do $\mathrm{Pb}$ ser o metal pesado presente em maior quantidade na crosta terrestre e suas liberações naturais serem provenientes de emissões vulcânicas, intemperismo geoquímico e névoas aquáticas, as atividades antrópicas são as principais responsáveis pela liberação desse mineral no ambiente (WHO, 1995; ATSDR, 2007). Segundo Barrero (2008), suas vistorias em Boquira, a pedido do Ministério Público Federal, possibilitaram identificar a instabilidade do material da pilha de rejeitos, o que representa potencial contaminação do solo e águas superficiais e subterrâneas devido os inúmeros canais de erosão que existem nessa pilha, fato constatado no trabalho de campo realizado em 2016 (Figura 2).

A disponibilidade dos metais pesados em solos contaminados define o potencial de absorção pelas plantas e de contaminação das águas por lixiviação. Os metais pesados que se encontram em forma solúvel no solo são facilmente absorvidos pelas plantas, aumentando a possibilidade de entrarem na cadeia trófica. Também podem ser lixiviados pelo perfil do solo, oferecendo risco de contaminação dos lençóis freáticos. Caso entre na cadeia trófica, os metais pesados podem causar sérios danos à saúde. De acordo com Alberto (2012), são desconhecidas pesquisas toxicológicas realizadas na população de Boquira. 


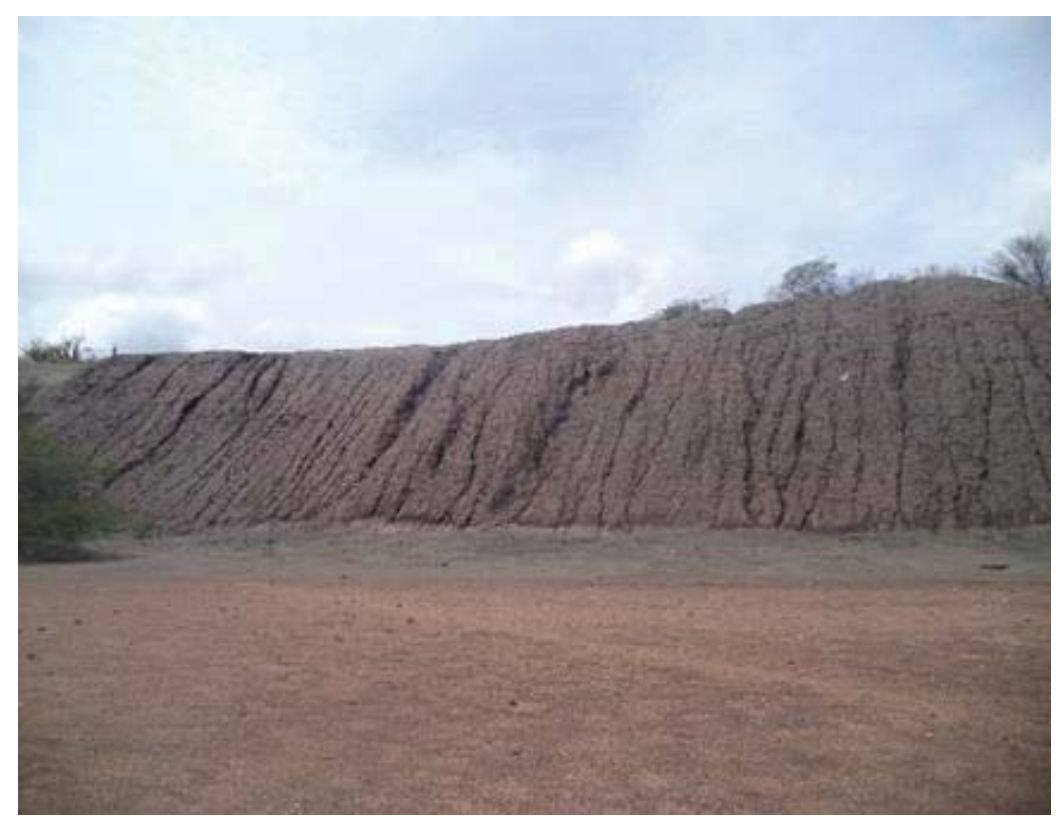

Figura 2 - Pilha de rejeitos com diversos canais de erosão Fonte: Trabalho de campo (2016).

Apesar de os estudos científicos sobre a toxicologia do $\mathrm{Pb}$ serem desenvolvidos há mais de um século, ainda são insuficientes as informações sobre os mecanismos de ação que originam os efeitos tóxicos desse metal. Os resultados da exposição ao $\mathrm{Pb}$ sobre a saúde humana devem ser estudados com maior profundidade. Nesse contexto, é de fundamental importância investigar os efeitos do $\mathrm{Pb}$ nos sistemas nervoso, endócrino e cardiovascular; nos ossos, fígado e rins; sobre a reprodução masculina, feminina e na formação dos fetos. Também é essencial esclarecer a possibilidade do $\mathrm{Pb}$ ter efeitos carcinogênicos e levar a disfunções psicológicas e neurocomportamentais (MOREIRA; MOREIRA, 2004).

Em Boquira, conforme pôde ser constatado nas três etapas dos trabalhos de campo, circulam rumores de que a ocorrência de doenças tais como câncer, problemas renais, pulmonares e psicológicos estão diretamente ligadas à extração e ao armazenamento inadequado dos rejeitos da mineração. Apesar do desconhecimento e da ausência de informações sobre o teor de metais no ambiente local, em especial do $\mathrm{Pb}$, e de sua relação com essas doenças, as atividades de reaproveitamento dos rejeitos através da instalação de uma indústria metalúrgica na cidade têm sido levantadas (ALBERTO, 2012).

\subsection{A injustiça ambiental e sua relação com o cenário encontrado em Boquira}

Para Acselrad et al. (2009, p. 9), o termo injustiça ambiental descreve o "fenômeno de imposição desproporcional dos riscos ambientais às populações menos dotadas de recursos financeiros, políticos e informacionais". Segundo os autores, é justamente nas populações mais pobres e desprovidas de poder que recai a maioria das externalidades negativas oriundas da extração dos recursos naturais e da subsequente disposição de rejeitos no ambiente. No Brasil, devido ao modelo de desenvolvimento adotado, tais fatos tornam-se corriqueiros (RIBEIRO, 2004; PORTO, 2005; ACSELRAD et al., 2009; MUNIZ, 2009).

Entende-se, pois, que o modelo de desenvolvimento prioritariamente adotado pelos mais diversos governos brasileiros está ligado ao que Martins e Caldas (2009, p. 215) denominam como a 
vertente de desenvolvimento pautada na "reprodução da lógica capitalista global", em que recursos e poder não são distribuídos de forma igualitária. Além disso, esse modelo potencializa a exploração desenfreada dos recursos naturais, tais como a extração mineral amplamente ocorrida em território nacional.

Historicamente, a mineração é um setor que está diretamente ligado a uma série de conflitos e ameaças nos territórios onde ele se desenvolve, causando, consequentemente, vários casos de injustiça ambiental. Nessa atividade, os resquícios da "busca pelo desenvolvimento" atribuem às populações locais o "pagamento" por essa busca, uma vez que são estas que ficam à mercê dos riscos diretos trazidos por essa atividade (WANDERLEY, 2011; MILANEZ; SANTOS, 2013). Como exemplo, cita-se o fato ocorrido em novembro de 2015, quando houve o maior "acidente" ambiental do Brasil: o rompimento da barragem de rejeitos da mineradora Samarco no munícipio de Mariana, MG. São milhares os atingidos pela lama de rejeitos e não se sabe, de fato, os reais danos causados ao ambiente e quanto tempo levará para a natureza se recompor, se é que isso vai acontecer.

Nesse contexto, para Porto (2005), as questões que envolvem a temática ambiental podem ser interpretadas como um desafio incontestável para as civilizações contemporâneas, haja vista que o assunto é extremamente relevante e deve embasar as discussões sobre desenvolvimento e sustentabilidade. Dessa forma, a saúde do trabalhador, que está ligada às ques- tões ambientais, deve ser considerada de forma simultânea às propostas e ações que busquem o desenvolvimento local, evitando que casos de injustiça ambiental aconteçam.

Ainda segundo Porto (2005), compreender e enfrentar as desigualdades impostas por um modelo desenvolvimentista que possibilita concentração de renda e poder é condição sine qua non para combater as injustiças ambientais existentes e fortalecer as lutas sociais por um desenvolvimento que seja construído de forma participativa e que não imponha às comunidades locais, muitas vezes vulneráveis, tais como agricultores familiares, indígenas, quilombolas, pescadores etc., as externalidades negativas de um modelo de desenvolvimento que aumenta as disparidades sociais e impacta, de forma negativa, os ecossistemas locais, essenciais para a sobrevivência e conservação dos modos de vida desses povos.

Diante desses entendimentos e da situação encontrada em Boquira, onde os rejeitos oriundos da extração do $\mathrm{Pb}$ foram abandonados próximos a bairros urbanos e a inúmeros estabelecimentos agrícolas, sem que nenhuma medida mitigadora prevista pela legislação ambiental nacional fosse tomada, e conhecendo os dados do PNUD (2013) que apontam que 60\% da população do município está ligada ao tema da pobreza, entende-se o cenário em Boquira como um caso de injustiça ambiental. Nos trabalhos de campo realizados em 2016, constatou-se que existem habitações a menos de 50 metros da pilha de rejeitos (Figura 3). 


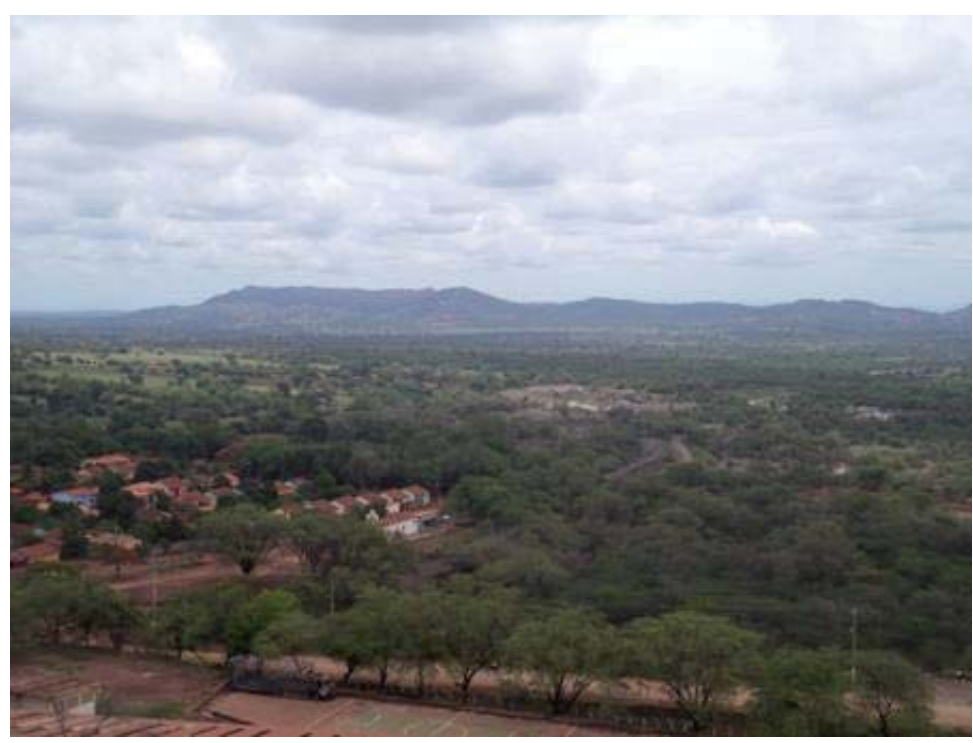

Figura 3 - Vista panorâmica da pilha de rejeitos e bairro urbano

Fonte: Trabalhos de campo (2016).

Corroborando para o cenário de injustiça ambiental, segundo Camelo (2006), a mina em Boquira não foi efetivamente fechada, mas abandonada, pois nenhuma das medidas legalmente estabelecidas para o encerramento de atividades mineradoras foi adotada. Em 2006, o Boletim Informativo do Departamento Nacional de Produção Mineral (DNPM), órgão do Ministério de Minas e Energia, ressaltou que tais rejeitos:

[...] apresentam teores de zinco, cádmio, arsênio, prata, além de chumbo e outros metais, cuja disposição não se encontra dentro de parâmetros ambientais aceitáveis, colocando em risco os mananciais e solos após o rompimento no passado de uma antiga barragem de contenção. [...] Tanto o DNPM como a Secretaria de Meio Ambiente da Bahia admitem como inadiável uma ação conjunta no sentido de formular e executar um projeto de despoluição capaz de resgatar a dignidade dos cidadãos, criando condições de sustentabilidade sócio-econômica e respeitando a geodiversidade e a biodiversidade locais. (DNPM, 2006, p. 4).
Alves e Bertolino (2014, p. 3) também comprovaram o risco a que a população de Boquira está exposta há décadas. De acordo com os autores, em sete amostras retiradas na pilha de rejeitos, todas apresentaram índice de $\mathrm{Pb}$ acima dos valores de referência disponibilizados pelo Conselho Nacional do Meio Ambiente (CONAMA), representando "um potencial risco à saúde da população que vive na sua proximidade". A pesquisa desses autores também comprovou a presença na pilha de rejeitos de outros minerais altamente poluentes, tais como: zinco, cádmio, arsênio, prata e ferro.

Em Santo Amaro, cidade baiana onde o material oriundo de Boquira era usado para produzir ligas de $\mathrm{Pb}$ pela Cobrac, a contaminação apresentou proporções alarmantes. Existem vários estudos que confirmam o grave problema de saúde pública nesse município. Em despacho datado de 2012 do Ministério Público Federal da $3^{\text {a }}$ Vara Federal da Seção Judiciária do estado da Bahia, que move ações contra a empresa poluidora, é destaque que Santo Amaro é "considerada a cidade mais poluída por chumbo do mundo". Assim, a Justiça Federal, por meio desse despacho, condenou a 
mineradora Plubum a recuperar os danos socioambientais por ela causados em Santo Amaro (BRASIL, 2012).

Em Boquira, a situação é bem diferente. No supracitado despacho é determinado que a ação pública contra a mineradora desmembre dos autos a cidade de Boquira, pois não existe um diagnóstico conclusivo sobre a situação nesse município. $\mathrm{O}$ referido documento descreve a necessidade de se realizar em Boquira uma perícia multidisciplinar que, segundo os resultados das pesquisas realizadas para elaboração deste artigo, nunca ocorreu.

\section{A REALIDADE PÓS-EXTRAÇÃO DO PB SOB A PERSPECTIVA DOS ATORES LOCAIS}

Segundo o gestor municipal, os riscos de contaminação oriundos da extração do $\mathrm{Pb}$ "são aqueles provocados pela bacia de rejeitos podendo levar problemas respiratórios ao redor da pilha através do efeito eólico" e a provável contaminação dos lençóis freáticos que estão localizados abaixo da pilha. Questionado sobre a existência de estudos que objetivem identificar e mensurar essa contaminação, o entrevistado declarou que empresas que pretendem "recuperar" o rejeito, ou seja, extrair e utilizar os minerais ali existentes, realizaram estudos na pilha para detectar a composição mineral nela existente. Segundo o gestor, "o que falta é a recuperação da área" que, segundo ele, "só deve ser feita pela empresa detentora do direito minerário".

O secretário municipal de educação, que declara desconhecer a existência de qualquer estudo científico que comprove ou mensure a contaminação, alegou que a preocupação com a situação em Boquira deriva, principalmente, dos inúmeros rumores que circulam na cidade apontando que os casos de doenças mais graves são atribuídos extração do $\mathrm{Pb}$. A nutricionista declarou conhecer esses rumores, porém, segundo ela, os produtos agropecuários locais são consumidos nas escolas do município e, de maneira geral, por toda a população local. Ao ser questionada sobre a qualidade da água utilizada nas escolas, e sobre qual sua percepção em relação à possibilidade desse recurso estar contaminado por $\mathrm{Pb}$, a nutricionista afirmou que, segundo a população local, os lençóis freáticos do município estão contaminados. Contudo, a entrevistada destacou que "mesmo assim, a água da região é utilizada pela população para o consumo e no preparo das refeições servidas nas unidades escolares".

Com o intuito de realizar novas pesquisas em Boquira, perguntou-se ao secretário de agricultura quantos estabelecimentos agrícolas existem num raio de $5 \mathrm{~km}$ da pilha de rejeitos. Segundo o entrevistado, é impossível se ter certeza, pois além de a sede do município estar nessa delimitação, não existe um mapa com o cadastramento dos imóveis. No entanto ele estima que devem existir aproximadamente 300 estabelecimentos nesse entorno. No que tange à produção agropecuária desses estabelecimentos, o secretário disse que, geralmente, os estabelecimentos agropecuários boquirenses produzem além de animais, milho, feijão, mandioca e cana; sendo que esses produtos muitas vezes são beneficiados originando farinha, tapioca, beiju, rapadura, bolos, biscoitos etc. A comercialização, segundo ele, é realizada no comércio local e em feiras livres, do próprio município e de outros municípios da região.

O secretário de meio ambiente informou que o lixão foi instalado sobre a pilha de rejeitos da extração de $\mathrm{Pb}$ no início de 1990, e que, em 2015, sete pessoas trabalhavam nesse local com coleta de materiais para reciclagem. Durante os trabalhos de campo realizados em 2016, constatou-se a presença de pessoas selecionando e carregando um caminhão com esses materiais bem como a existência de animais como caprinos e suínos pastejando nessa área (Figuras 4 e 5). 


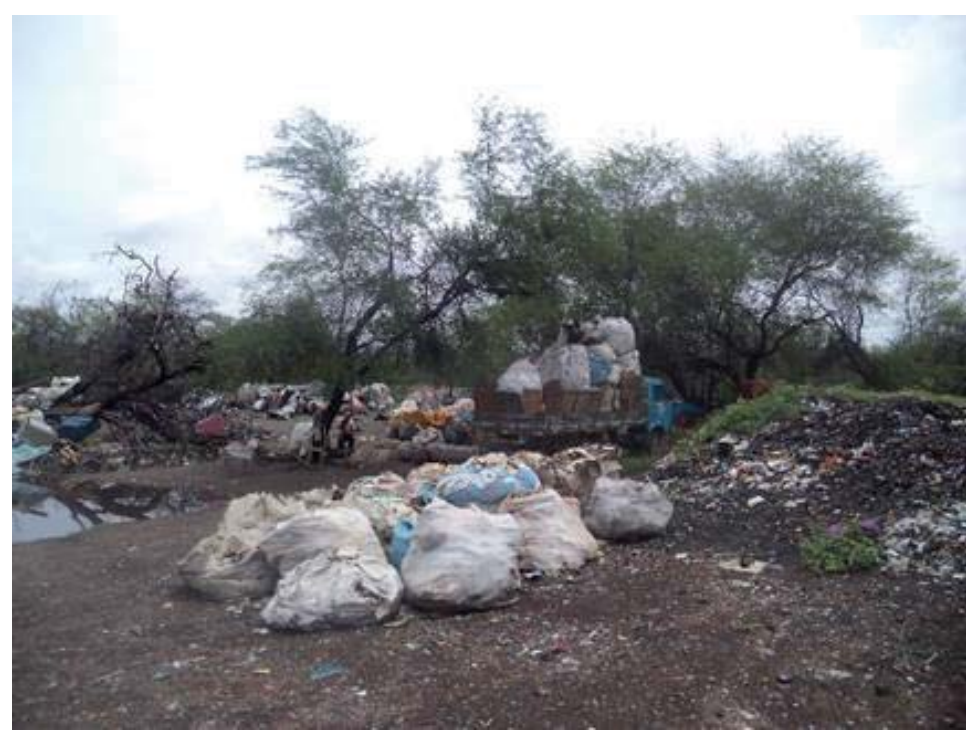

Figura 4 - Coleta de materiais recicláveis no lixão instalado sobre a pilha de rejeitos

Fonte: Trabalho de campo (2016).

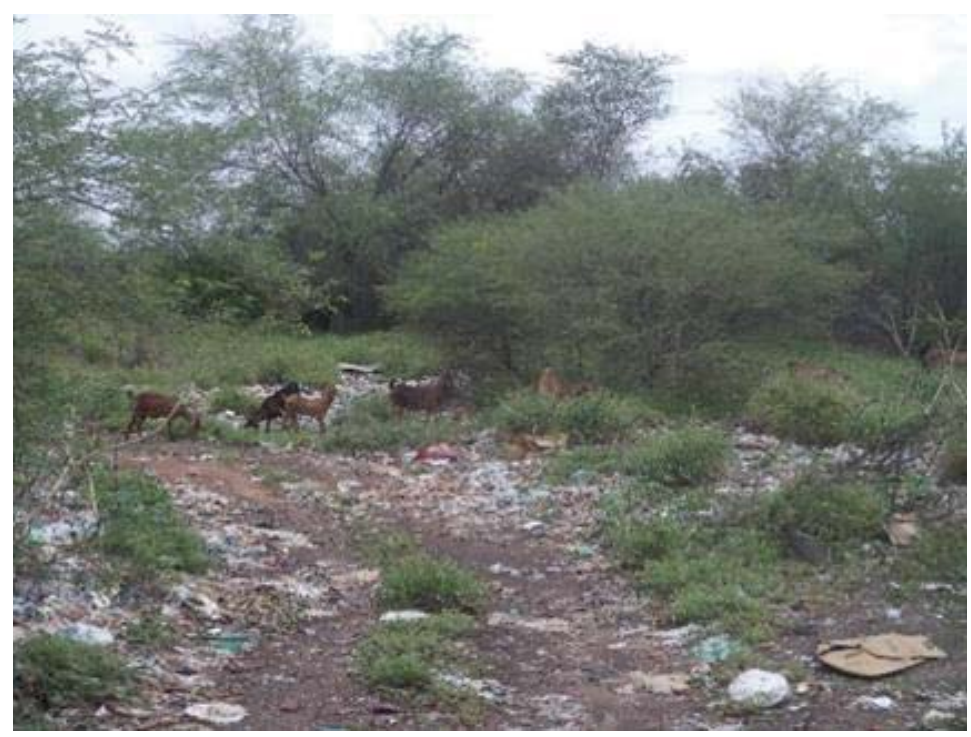

Figura 5 - Animais pastejando em meio ao lixão instalado sobre a pilha de rejeitos

Fonte: Trabalho de campo (2016).

Questionado se possuía conhecimento sobre algum trabalho que objetivasse identificar ou mensurar a possível contaminação dos recursos naturais, ou da população, pela extração do $\mathrm{Pb}, \mathrm{o}$ secretário de meio ambiente disse que existem estudos para o reaproveitamento dos resíduos e que ocorreram algumas reuniões em Boquira para tratar da pro- vável contaminação. Contudo, segundo suas informações, até o momento nunca foi apresentada à sociedade boquirense nenhuma conclusão sobre esse assunto. Sobre os rumores que os recursos hídricos estão contaminados por $\mathrm{Pb}$, o secretário descarta essa hipótese, pois, segundo ele, o SAAE realiza análises periódicas nas águas e nunca detectou tal contaminação. 
Por sua vez, o representante do SAAE explicou que a instituição realiza análises na água que abastece a sede do município, e que estas visam identificar e avaliar índices de coliformes fecais e outras impurezas, não metais pesados. Segundo ele, a Companhia de Pesquisa de Recursos Minerais (CPRM) retirou amostras da água para realizar análises sobre metais pesados, entretanto os resultados ainda não foram repassados ao município.

A secretária de saúde afirmou que "não existem análises para identificar a presença do $\mathrm{Pb}$ ou outro material oriundo da extração do chumbo" na água de Boquira. Tendo por base os rumores que dizem que as doenças mais graves do município estão ligadas à extração do $\mathrm{Pb}$, questionou-se à secretária se a prefeitura concorda com essas suspeitas, e o porquê da concordância ou discordância. Segundo ela, a prefeitura desconcorda. A secretária relatou que ocorreram casos de silicose em funcionários da mineração na época da extração. Segundo Melo e Zago (2012, p. 46) “a silicose é uma doença pulmonar [...] considerada irreversível e crônica". A secretária mencionou também que os casos de câncer no município cresceram na mesma proporção dos casos dessa doença na Bahia e no Brasil, descartando assim qualquer ligação da ocorrência de câncer em Boquira com a extração do $\mathrm{Pb}$.

O médico que trabalhou na mineradora descreveu que, quando lá atou, foram realizados, por diversas vezes, exames nos operários para verificar a taxa de $\mathrm{Pb}$ no sangue, havendo apenas um caso em que um operário estava com taxas "um pouco elevadas"; esse funcionário, que continua morando em Boquira, foi afastado para o devido tratamento e, pelo que o médico diz saber, "não apresenta nenhuma doença que possa ser relacionada ao contato com o minério de chumbo". O entrevistado descreveu que, após o encerramento da mineração, chegaram a Boquira profissionais de um laboratório de Salvador que realizaram coletas de sangue nos ex-funcionários da mineradora. Entretanto ele não soube dos resultados e acredita que nenhuma das pessoas que forneceram sangue foi informada desses resultados.

Em relação aos nove agricultores familiares que acessavam o PNAE, sete declararam conhecer algum caso de doença ocasionada por contaminação pelo $\mathrm{Pb}$, um deles relata ter conhecido uma pessoa que faleceu por causa disso. Seis agricultores declararam saber que a extração de $\mathrm{Pb}$ no município pode ter causado contaminação, tanto dos recursos naturais quanto da população local. Todos os agricultores entrevistados disseram que nunca houve em seus estabelecimentos nenhuma pesquisa para detectar a possibilidade de contaminação por $\mathrm{Pb}$ e, tampouco, possuem conhecimento de que qualquer agricultor da região tenha tido tais pesquisas em seus estabelecimentos.

\section{CONSIDERAÇÕES FINAIS}

A preocupação com a possível contaminação pelo $\mathrm{Pb}$ e seus efeitos no município, em diferentes níveis, foi confirmada por todos os atores que participaram da pesquisa. Todos eles acreditam ser necessário realizar estudos que visem identificar e, ou, mensurar a contaminação. O próprio gestor municipal declarou o risco de contaminação pela ação dos ventos, pois é sabido que a inalação da poeira lançada na atmosfera é vetor de contaminação, bem como a provável contaminação dos lençóis freáticos onde os rejeitos estão depositados.

Constatou-se, também, certo desencontro e desconhecimento por parte dos atores entrevistados sobre os estudos existentes e os reais riscos de contaminação. Por exemplo, a secretária municipal de saúde disse acreditar que a extração do chumbo não possui relação com os casos de câncer existentes no município, pois os casos dessa doença cresceram em Boquira 
na mesma proporção do estado da Bahia e do Brasil. Tal fato não significa que os casos de câncer em Boquira não possuem ligação com a atividade mineradora que lá existiu; principalmente sabendo que chumbo, cádmio e arsênio, elementos comprovadamente presentes na pilha de rejeitos da extração do $\mathrm{Pb}$, são considerados agentes carcinogênicos pelo Instituto Nacional de Câncer (INCA), órgão auxiliar do Ministério da Saúde.

Diante de alguns relatos, surgem mais dúvidas e preocupações: se realmente os resultados da coleta de sangue nos ex-funcionários não foram repassados à comunidade local, qual o motivo? Por que o poder público, nas esferas municipal, estadual e federal, ao longo das décadas praticamente ficou inerte diante da relevância da situação? O DNPM e a Secretaria Estadual do Meio Ambiente da Bahia admitiram, em 2006, a necessidade de uma ação conjunta que objetivasse a despoluição em Boquira, resgatando assim a "dignidade dos cidadãos". Contudo, após dez anos, a única ação que a presente pesquisa identificou foi o fato da CPRM ter retirado amostras de água de poços tubulares. Entretanto, segundo os atores que participaram desta pesquisa, os resultados ainda são desconhecidos. Fatos assim apontam para inação governamental diante da problemática encontrada em Boquira.

Diante do exposto, em que as ações em prol do "desenvolvimento" geraram este preocupante cenário aqui descrito, entende-se que, para o processo de resolução da injustiça ambiental encontrado em Boquira se inicie, é relevante expor esse problema. Inclusive com o intuito de que os governos, e as instituições ligadas a eles, busquem promover ações que possibilitem identificar e mensurar, caso exista, a contaminação neste município. A complexidade da situação aqui apresentada tem como agravante a importância da agricultura familiar para o sustento e alimentação das famílias locais. Isto intensifica a urgência de pesquisas que possibilitem realizar um diagnóstico conclusivo para averiguar e mensurar se a extração do chumbo contaminou os recursos naturais locais, sendo também responsável por problemas de saúde da população boquirense.

\section{REFERÊNCIAS}

ACSELRAD, H.; MELLO, C. C. A.; BEZERRA, G. N. O que é justiça ambiental. Rio de Janeiro: Garamond, 2009. 160 p.

AGENCY FOR TOXIC SUBSTANCES AND DIASES REGISTRY (ATSDR). Toxicological profile for lead. Syracuse: U.S. Department of Health and Human Services, Public Health Service. Atlanta, USA, 2007. 582p. Disponível em: <http://www.atsdr.cdc. gov/toxprofiles/ tp13.pdf.> Acesso em: 23 set. 2015.

ALBERTO,L. Perspectivas para a mineração de chumbo no Estado da Bahia. In: FERNANDES, Francisco Rego Chaves; BERTOLINO, Luiz Carlos; EGLER, Silvia (Ed.). 2. ed. Projeto Santo Amaro - BA: aglutinando ideias, construindo soluções. Rio de Janeiro: CETEM/MCTI, 2012. p. 10-18. Disponível em: <http://www.cetem. gov.br/santo_amaro/pdf/livrocompleto.pdf > Acesso em: 27 set. 2015.

ALVES, F. E. A.; BERTOLINO, L.C. Estudo da contaminação do rejeito da Mineração de Chumbo em Boquira (BA). JORNADA DE INICIAÇÃO CIENTÍFICA-CETEM, 22., Rio de Janeiro, 2014. Disponível em: <http://mineralis.cetem.gov.br/bitstream/ handle/cetem/1519/Felipe\%20Emerson \%20 Andr\%C3\% A9\%20Alves.pdf?sequence $=1>$. Acesso em: 12 out. 2015.

ANDRADE, A. X. A.;SILVA, G. B.;ANDRADE, N. A. X. O acesso às políticas públicas no semiárido e seu reflexo na heterogeneidade da agricultura familiar: o PNAE em Boquira-BA. Extensão Rural, Santa Maria, RS, v. 22, n. 2, p. 79-97, abr./jun. 2015. Disponível em: <http:/ / cascavel.ufsm.br/revistas/ojs.2.2/index. php/extensaorural/article/view/15443/ pdf $>$. Acesso em: 12 dez. 2015.

BARRERO, F. M. C. Análise de áreas degradadas pós-mineração em municípios da Bacia do rio Paramirim. Relatório Técnico. Salvado, BA, jun. 2008. 
BRASIL. Terceira Vara Federal da Seção Judiciária do estado da Bahia. Manifestação da procuradora da República Caroline Rocha de Queiroz. Salvador, BA, 22 de novembro de 2012. Disponível em: <http:/ / www.prba.mpf.br/ mpf-noticias/meio-ambiente-e-patrimonio-cultural / ManifestaçãoCarolineRochaQueiroz_casoamianto.pdf>. Acesso em: jan. 2015.

CAMELO, M. S. M. Fechamento de mina: análise de casos selecionados sob os focos ambiental, econômico e social. 2006. 127f. Dissertação (Mestrado em Engenharia Geotécnica) - Núcleo de Geotécnica da Escola de Minas da Universidade Federal de Ouro Preto, Ouro Preto, MG, 2006. Disponível em: <http:/ / www.repositorio.ufop.br/handle/123456789/ 2355> Acesso em: 16 ago. 2015.

DEPARTAMENTO NACIONAL DE PRODUÇÃO MINERAL (DNPM). DNPM e Secretaria de Meio Ambiente da Bahia se reúnem em Salvador. Boletim Informativo do Departamento Nacional de Produção Mineral - Ministério de Minas e Energia, Brasília, DF, ano 2, n. 15, mar. 2006. Disponível em: <http://www2.dnpm.gov.br/mostra_arquivo.asp? IDBancoArquivo Arquivo= 727>. Acesso em: 30 out. 2015.

DUARTE, R. P. S.; PASQUAL, A. Avaliação do cádmio $(\mathrm{Cd})$, chumbo $(\mathrm{Pb})$, Níquel $(\mathrm{Ni})$ e zinco $(\mathrm{Zn})$ em solos, plantas e cabelos humanos. Energia na Agricultura, Botucatu, SP, v. 15, n. 1, p. 46-58, 2000.

FARIAS, C. E. G. Mineração e meio ambiente no brasil. Relatório Preparado para o CGEE/ PNUD. Brasília, DF, out. 2002, 40p. Disponível em: <http:/ / www.cgee.org.br/ arquivos/ estudo011_02.pdf>. Acesso em: 26 ago. 2015.

FERRAN, A. P. N. A Mineração e a flotação no Brasil - uma perspectiva histórica. Brasília, DF: Departamento Nacional de Produção Mineral (DNPM), Ministério de Minas e Energia, 2007. Disponível em: <http:/ / www. dnpm.gov.br/dnpm/publicacoes-economiamineral/arquivos/a-mineracao-e-a-flotacaono-brasil.pdf.> Acesso em: 30 jul. 2015.

FLICK, U. Desenho da pesquisa qualitativa. Porto Alegre, RS: Artmed, 2009. 164p. (Coleção Pesquisa Qualitativa).

GUILHERME L, R. G.; MARQUES, J. J.; PIERANGELI, M. A. P.; QUEIRÓZ, Z.;
CAMPOS, M. L.; MARCHI, G. Elementostraço em solos e sistemas aquáticos. Tópicos em Ciência do Solo, Viçosa, MG, n. 4, p. 345390, 2005.

INSTITUTO BRASILEIRO DE GEOGRAFIA E ESTATÍSTICA (IBGE). Censo agropecuário, 2006. Disponível em: <http://www.ibge. gov.br/home/estatistica/economia/ agropecuaria/censoagro/2006/>. Acesso em: 25 jun. 2016.

MARCONI, M. A.; LAKATOS, E. M. Metodologia científica. 5. ed. São Paulo: Atlas, 2003. 310p.

. Metodologia científica. 6. ed. São Paulo: Atlas, 2007. 312p.

MARTINS, L.; FONSECA, R.; DIAS, N.; ARAÚJO, A. P.; PINHO, A. C.; Análise geoquímica dos sedimentos de um curso de água contaminado por metais pesados na área de uma unidade fabril metalúrgica, Minas Gerais, Brasil. Comunicações Geológicas, Porto, Portugal, v. 101, Especial II, p. 1023-1026, 2014. Disponível em: <http://www.lneg. pt/ download/9703/89_2966_ART_CG14_ ESPECIAL_II.pdf>. Acesso em: 21 ago. 2015.

MARTINS, R. D.; CALDAS, E. L. Visões do desenvolvimento local: uma análise comparada de experiências brasileiras. Interações, Campo Grande, MS, v. 10, n. 2, p. 207-218, jul./dez. 2009. Disponível em: <http:/ / www. interacoes.ucdb.br/article/view/391/441>. Acesso em: 2 jun. 2016.

MCBRIDE, M. B. Environmental chemistry of soils. New York, USA: Oxford University Press, 1994. 406 p.

MELO, R. S. S.; ZAGO, M. M. F. Os sentidos da silicose atribuídos por trabalhadores de pedreiras adoecidos. Texto Contexto Enfermagem, Florianópolis, SC, v. 21, n. 4, p. 845-853, out/dez. 2012.

MILANEZ, B.; SANTOS, R. S. P. Neoextrativismo no Brasil? Uma análise da proposta do novo marco legal da mineração. Revista Pós Ciências Sociais, São Luís, MA, v. 10, n. 19, p. 119-148, jan./jun. 2013.

MOREIRA, F. R.; MOREIRA, J. C. Os efeitos do chumbo sobre o organismo humano e seu significado para a Saúde. Revista Panamericana de Salud Pública, Washington, USA, v. 15, n. 2, fev. 2004. 
MUNIZ, L. M. Ecologia política: o campo de estudo dos conflitos sócio-ambientais. Revista Pós Ciências Sociais, São Luís, MA, v. 6, n. 12, 2009.

OLIVEIRA, M. R.; HORN, A. H. Comparação da concentração de metais pesados nas águas do rio São Francisco em Três Marias, desde 1991 até hoje, relacionando a atuação da CMM-Três Marias. Geonomos, Belo Horizonte, MG, v. 14, n. 2, p. 55-63, 2006. Disponível em: <http://www.igc.ufmg.br/portaldeperiodicos/index.php/geonomos/article/ view/110/90>. Acesso em: 20 nov. 2015.

OLIVEIRA, L. R. Metais pesados e atividade enzimática em Latossolos tratados lodo de esgoto e cultivados com milho. 2008. 108 f. Tese (Doutorado em Agronomia - Produção Vegetal) - Faculdade de Ciências Agrárias e Veterinárias, Universidade Estadual Paulista, Jaboticabal, SP. 2008. Disponível em: < http://www.fcav. unesp.br/download/pgtrabs/pv/d/2631. pdf>. Acesso em: 25 out. 2015.

PORTO, M. P. Saúde do trabalhador e o desafio ambiental: contribuições do enfoque ecossocial, da ecologia política e do movimento pela justiça ambiental. Ciência \& Saúde Coletiva, Rio de Janeiro, v. 10, n. 4. p. 829-839, out./dez. 2005. Disponível em: <http:// www.scielo.br/pdf/csc/v10n4/a08v10n4. pdf>. Acesso em: 24 out. 2015.

PROGRAMA DASNAÇÕES UNIDAS PARA O DESENVOLVIMENTO (PNUD). Atlas do Desenvolvimento Humano no Brasil. 2013. Disponível em: <http://www.pnud.org.br/ IDH/Default.aspx?indiceAccordion=1\&li=li_ AtlasMunicipios>. Acesso em: 27 set. 2015.

RIBEIRO, H. Saúde pública e meio ambiente: evolução do conhecimento e da prática, alguns aspectos éticos. Saúde e Sociedade, São Paulo, v. 13, n. 1, p. 70-80, 2004.

SOBRAL, L. G. S.; OLIVEIRA, D. M.; SOUZA, D. E. G.; SILVA, S. C. A. F.; BRAGA, P.
F. A. Metalurgia do chumbo: processos de produção e refino. In: FERNANDES, Francisco Rego Chaves; BERTOLINO, Luiz Carlos; EGLER, Silvia (Ed.). 2. ed. Projeto Santo Amaro - BA: aglutinando ideias, construindo soluções. Rio de Janeiro: CETEM/MCTI, 2012. p. 150-173. Disponível em: <http://www. cetem.gov.br/santo_amaro/pdf/cap12.pdf> Acesso em: 27 ago. 2015.

SOUZA, K. V.; LIMA M. F. S. Passivos socioambientais da minerometalurgia do chumbo em Santo Amaro e Boquira (BA), Vale do Ribeira (PR) e Mauá da Serra (PR). In: FERNANDES, Francisco Rego Chaves; BERTOLINO, Luiz Carlos; EGLER, Silvia (Ed.). 2. ed. Projeto Santo Amaro - BA: aglutinando ideias, construindo soluções. Rio de Janeiro: CETEM/MCTI, 2012. p. 19-41. Disponível em: <http://www.cetem.gov.br/santo_amaro/ pdf/cap5.pdf>. Acesso em: 27 ago. 2015.

SUPERINTENDÊNCIA DE ESTUDOS ECONÔMICOS E SOCIAIS DA BAHIA (SEI). Estatística dos municípios baianos. Salvador, BA, v. 19, p. 182, 2011. Disponível em: <http:// www.sei.ba.gov.br/images/ publicacoes/ sumario/estatisticasmunicipios/sumario_ est_mun_v4_bacia_do_paramirim.pdf $>$. Acesso em: 26 set. 2015.

WANDERLEY, L. J. M. “Atingidos por mineração": conflitos e movimentos sociais na Amazônia brasileira. ENCONTRO ANUAL DA ASSOCIAÇÃO NACIONAL DE PÓSGRADUAÇÃO E PESQUISA EM CIÊNCIAS SOCIAIS, 35., Caxambu, MG, 2011. Anais Eletrônicos... Disponível em: <http://anpocs. org/portal/arquivos/35_Encontro/GTs/ GT03/luiswanderley.pdf>. Acesso em: 20 nov. 2015.

WORLD HEALTH ORGANIZATION (WHO). Environmental health criteria 165: inorganic lead. Geneva, USA, 1995. 300p. Disponível em: <http://www.who.int/ipcs/ features/ lead..pdf> Acesso em: 24 jul. 2015

\section{Sobre os autores:}

Álvaro Antônio Xavier de Andrade: Graduação em Agronomia pela Universidade do Estado da Bahia. Especialização em Planejamento Ambiental com ênfase em Educação Ambiental pela Unyahna. Mestre em Extensão Rural pela Universidade Federal de Viçosa (UFV). Doutorando em Extensão Rural pela Universidade Federal de Viçosa. E-mail: aaxandrade2@hotmail.com 
Emanuelle Mercês Barros Soares: Graduação em Agronomia pela Universidade do Estado da Bahia. Mestrado pela Universidade Federal de Lavras e Doutorado na Universidade Federal de Viçosa em Solos e Nutrição de Plantas, e área de concentração em Matéria Orgânica do Solo (MOS). Professora adjunta do Departamento de Solos da Universidade Federal de Viçosa. E-mail: emanuelle.soares@ufv.br

Dênis Antônio da Cunha: Graduação em Ciências Econômicas, Mestrado e Doutorado em Economia Aplicada pela Universidade Federal de Viçosa (UFV). Professor Adjunto e Orientador dos Programas de Pós-Graduação em Economia Aplicada (PPGEA) e Extensão Rural (PPGER) da Universidade Federal de Viçosa. Bolsista do Programa Pesquisador Mineiro (FAPEMIG). Líder do Grupo de Pesquisa "Economia dos Recursos Naturais e Ambientais", vinculado ao PPGEA/UFV. E-mail: denisufv@gmail.com

Marcelo Leles Romarco de Oliveira: Doutorado em Ciências Sociais pelo CPDA pela Universidade Federal Rural do Rio de Janeiro, mestrado em Extensão Rural pela Universidade Federal de Viçosa, especialização em História do Brasil Pós-1930 pela Universidade Federal Fluminense e graduação em Administração pela Universidade Federal de Lavras. Professor do Departamento de Economia Rural da Universidade Federal de Viçosa. Atualmente, tem se dedicado a pesquisas junto a comunidades extrativistas na Amazônia brasileira. E-mail: marceloromarco@gmail.com 
